Technical Note

\title{
Synthesis and Structural Identification of a Biaryl Ether-Linked Zearalenone Dimer
}

\author{
Julia Keller ${ }^{1}$, Luisa Hantschke ${ }^{1}$, Hajo Haase ${ }^{2} \mathbb{D}$ and Matthias Koch ${ }^{1, * \mathbb{D}}$ \\ 1 Department Analytical Chemistry, Reference Materials, Bundesanstalt für Materialforschung und \\ -prüfung (BAM), Richard-Willstätter-Straße 11, 12489 Berlin, Germany; juliakeller19@yahoo.de (J.K.); \\ luisa.hantschke@web.de (L.H.) \\ 2 Department of Food Chemistry and Toxicology, Technische Universität Berlin, Gustav-Meyer-Allee 25, \\ 13355 Berlin, Germany; haase@tu-berlin.de \\ * Correspondence: matthias.koch@bam.de; Tel.: +49-30-8104-1170
}

Received: 14 September 2018; Accepted: 11 October 2018; Published: 12 October 2018

check for updates

\begin{abstract}
A new dimer of the food-relevant mycotoxin zearalenone was isolated after electrochemical and chemical oxidation. The structure was determined as a 16-O-15'-biaryl ether-linked dimer based on spectroscopic analyses $\left({ }^{1} \mathrm{H}\right.$ - and ${ }^{13} \mathrm{C}-\mathrm{NMR}, \mathrm{COSY}, \mathrm{HMBC}$, and HSQCAD) and high-resolution mass spectrometry analysis (Q-TOF).
\end{abstract}

Keywords: mycotoxin; dimerization; HRMS; NMR

\section{Introduction}

The fungal secondary metabolite zearalenone (ZEN) is found worldwide and is primarily produced by Fusarium species [1-3]. Often found in common crops like corn, wheat, rice, soybeans, sorghum, spices, or walnuts, it poses a health risk to human and animals [4-6]. As mycoestrogen, it causes swelling of the uterus and vulva, infertility, and atrophy of ovaries reported in swine and cattle $[7,8]$. Several metabolites derived from plants, fungi, and mammalian metabolism are part of ongoing research due to unknown toxic effects and occurrence [9-12].

Oxidative reactions of ZEN lead to hydroxylated species obtained from in vitro assays with liver microsomes of rodent and non-rodent liver cells $[13,14]$. A recent study proposed the production of numerous hydroxylated as well as new dimeric species of ZEN by using electrochemistry coupled to mass spectrometry [15]. The production, isolation, and structural elucidation of the predominant dimeric species is now achieved.

\section{Results and Discussion}

Compound 1 was obtained as a pale orange solid substance after electrochemical and chemical oxidation of ZEN with a molecular formula of $\mathrm{C}_{36} \mathrm{H}_{42} \mathrm{O}_{10}$, which was measured by high-resolution mass spectrometry with $\mathrm{m} / \mathrm{z} 633.2658[\mathrm{M}-\mathrm{H}]^{-}$in an ESI negative ionization mode (theoretical exact mass $m / z$ 633.2702), as previously described [15]. The MS/MS measurements of compound 1 revealed a fragment with $\mathrm{m} / \mathrm{z} 589.2756$, which is due to the loss of $\mathrm{CO}_{2}$, and a fragment with $\mathrm{m} / \mathrm{z} 565.2746$ because of a loss of $\mathrm{C}_{3} \mathrm{O}_{2}$. The signal with $\mathrm{m} / z 491.1658$, corresponds to a loss of $\mathrm{C}_{8} \mathrm{H}_{4} \mathrm{O}_{2}$, which led to the fragment $m / z 447.1763$ after the loss of $\mathrm{CO}_{2}$ (Supplement Figure S1). The assumed fragments and their chemical formulas with theoretical exact masses are shown in Figure 1. 


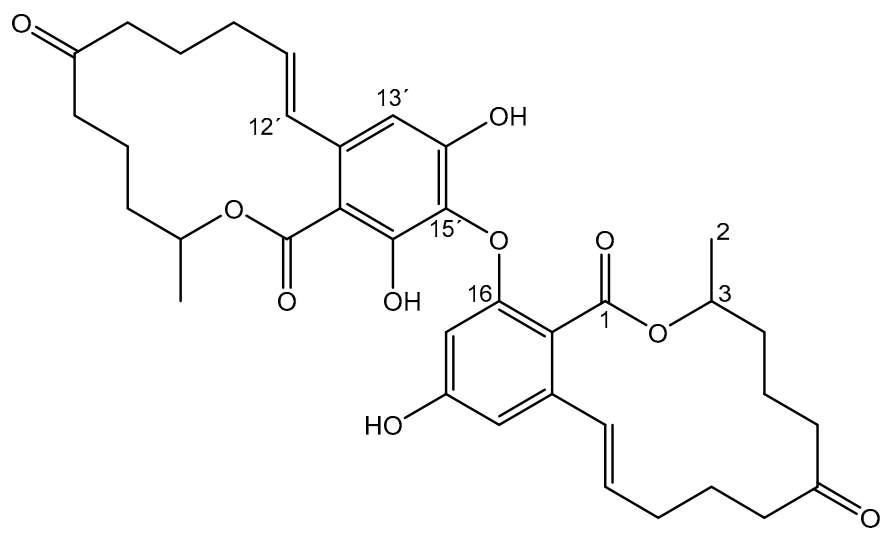

Figure 1. Structure of compound 1.

The ${ }^{1} \mathrm{H}-\mathrm{NMR}$ spectrum of compound 1 measured at $400 \mathrm{MHz}$ in $\mathrm{MeOH}-d_{4}$ gave the following information with 1.00-2.85 (m, H, J = 6.8 Hz), $1.34(\mathrm{~d}, 3 \mathrm{H}, J=6.2 \mathrm{~Hz}), 1.39(\mathrm{~d}, 3 \mathrm{H}, J=6.4 \mathrm{~Hz}), 5.06-5.16$ $(\mathrm{m}, 1 \mathrm{H}), 5.20-5.36(\mathrm{~m}, 1 \mathrm{H}), 5.71(\mathrm{ddd}, 1 \mathrm{H}, J=4.0,9.8,15.6 \mathrm{~Hz}), 5.77(\mathrm{~d}, 1 \mathrm{H}, J=2.1 \mathrm{~Hz}), 6.03(\mathrm{~d}, 1 \mathrm{H}$, $J=4.4,9.6,14.6 \mathrm{~Hz}), 6.34-6.41(\mathrm{~m}, 2 \mathrm{H}), 6.42(\mathrm{~s}, 1 \mathrm{H})$, and $6.58(\mathrm{~d}, 1 \mathrm{H}, J=2.1 \mathrm{~Hz})$. The ${ }^{13} \mathrm{C}-\mathrm{NMR}$ measurements with $100 \mathrm{MHz}$ revealed the following chemical shifts with 20.2, 21.0, 22.1, 22.6, 23.4, 32.4, 35.9, 37.6, 38.3, 43.9, 44.7, 73.7, 74.3, 100.8, 104.3, 106.7, 126.4, 130.2, 134.4, 137.2, 139.4, 158.0, 161.0, 172.1, 213.8, and 214.1 ppm (Supplement Figures S2 and S3). The assignments of the carbons and protons are summarized in Table 1.

Table 1. ${ }^{1} \mathrm{H}-\mathrm{NMR}$ and ${ }^{13} \mathrm{C}-\mathrm{NMR}$ data of $\mathbf{1}\left(400 / 100 \mathrm{MHz}\right.$, Methanol- $\left.d_{4}\right)$.

\begin{tabular}{ccc}
\hline Position & ${ }^{\mathbf{1}} \mathbf{H}(\mathbf{p p m})$ & ${ }^{\mathbf{3}} \mathbf{C}(\mathbf{p p m})$ \\
\hline $1,1^{\prime}$ & - & $213.8,214.1$ \\
2 & $1.39(\mathrm{~d}, J=6.4 \mathrm{~Hz}, 3 \mathrm{H})$ & 35.9 \\
3 & $5.20-5.36(\mathrm{~m}, 1 \mathrm{H})$ & 73.7 \\
$10,10^{\prime}$ & - & $32.4,32.4$ \\
11 & $6.03(\mathrm{ddd}, J=4.4,9.6,14.6 \mathrm{~Hz}, 1 \mathrm{H})$ & 134.4 \\
12 & $6.38-6.41(\mathrm{~m}, 1 \mathrm{H})$ & 130.2 \\
13 & $6.58(\mathrm{~d}, J=2.1 \mathrm{~Hz}, 1 \mathrm{H})$ & 106.7 \\
14 & - & 161.0 \\
15 & $5.77(\mathrm{~d}, J=2.1 \mathrm{~Hz}, 1 \mathrm{H})$ & 100.8 \\
$2^{\prime}$ & $1.34(\mathrm{~d}, J=6.2 \mathrm{~Hz}, 3 \mathrm{H})$ & 35.9 \\
$3^{\prime}$ & $5.06-5.16(\mathrm{~m}, 1 \mathrm{H})$ & 74.3 \\
$11^{\prime}$ & $5.71(\mathrm{ddd}, J=4.0,9.8,15.6 \mathrm{~Hz}, 1 \mathrm{H})$ & 137.2 \\
$12^{\prime}$ & $6.34-6.37(\mathrm{~m}, 1 \mathrm{H})$ & 126.4 \\
$13^{\prime}$ & $6.42(\mathrm{~s}, 1 \mathrm{H})$ & 104.3 \\
\hline
\end{tabular}

The ${ }^{1} \mathrm{H}-\mathrm{NMR}$ and COSY spectra revealed two aromatic systems (Supplement Figures S2 and S4). One of these aromatic systems contained two protons $(\mathrm{d} 6.58 \mathrm{ppm}, 1 \mathrm{H}, J=2.1 \mathrm{~Hz}$, and d $5.77 \mathrm{ppm}$, $1 \mathrm{H}, J=2.1 \mathrm{~Hz}$ ) while the second aromatic system had only one proton (s $6.42 \mathrm{ppm}, 1 \mathrm{H})$. From this observation, the structures connected over the C-C linkages $15,15^{\prime}, 13,13^{\prime}$, and $13,15^{\prime}$ can be excluded since these dimers would have two aromatic systems with only one proton. Thus, only dimers having an C-O-C ether bridge between the monomers are possible. The COSY spectrum showed nearly identical chemical structures for the spectral part of the molecule (Supplement Figure S4). As a result, the dimerization of two ZEN molecules is only likely over an ether-link between 14-O-13', 14-O-15', $16-\mathrm{O}-13^{\prime}$, or $16-\mathrm{O}-15^{\prime}$. The HMBC spectrum $(8 \mathrm{~Hz})$ indicates a common coupling partner of the single aromatic proton and $12^{\prime}-\mathrm{H}$, which is located in the aromatic-olefinic region (Supplement Figure S5). Due to the spatial proximity, it should be at the singlet $(6.42 \mathrm{ppm})$ and, as a result, act around the $13^{\prime}-\mathrm{H}$ position. Consequently, an O-15'-linkage is conceivable. 
The observed significant difference of the chemical shifts of 3-H and $3^{\prime}-\mathrm{H}$ indicated a different chemical environment. For a C-14 link, the closer chemical environment of 3-H and $3^{\prime}-\mathrm{H}$ would be very similar. A C-16 link, on the other hand, would be a greater steric influence and inductive effects would occur. Thus, the compound 16-O-15'-biaryl ether bond is the most likely structure, which is shown in Figure 2. Whether this dimer can be found naturally in food or feed remains to be analyzed in detail. Especially in plants, lichen, bacteria, and fungi regio-selective and stereo-selective biaryl C-C and biaryl ether C-O-C linkages are often found and it is conceivable that dimers of ZEN might not be uncommon in nature [16].

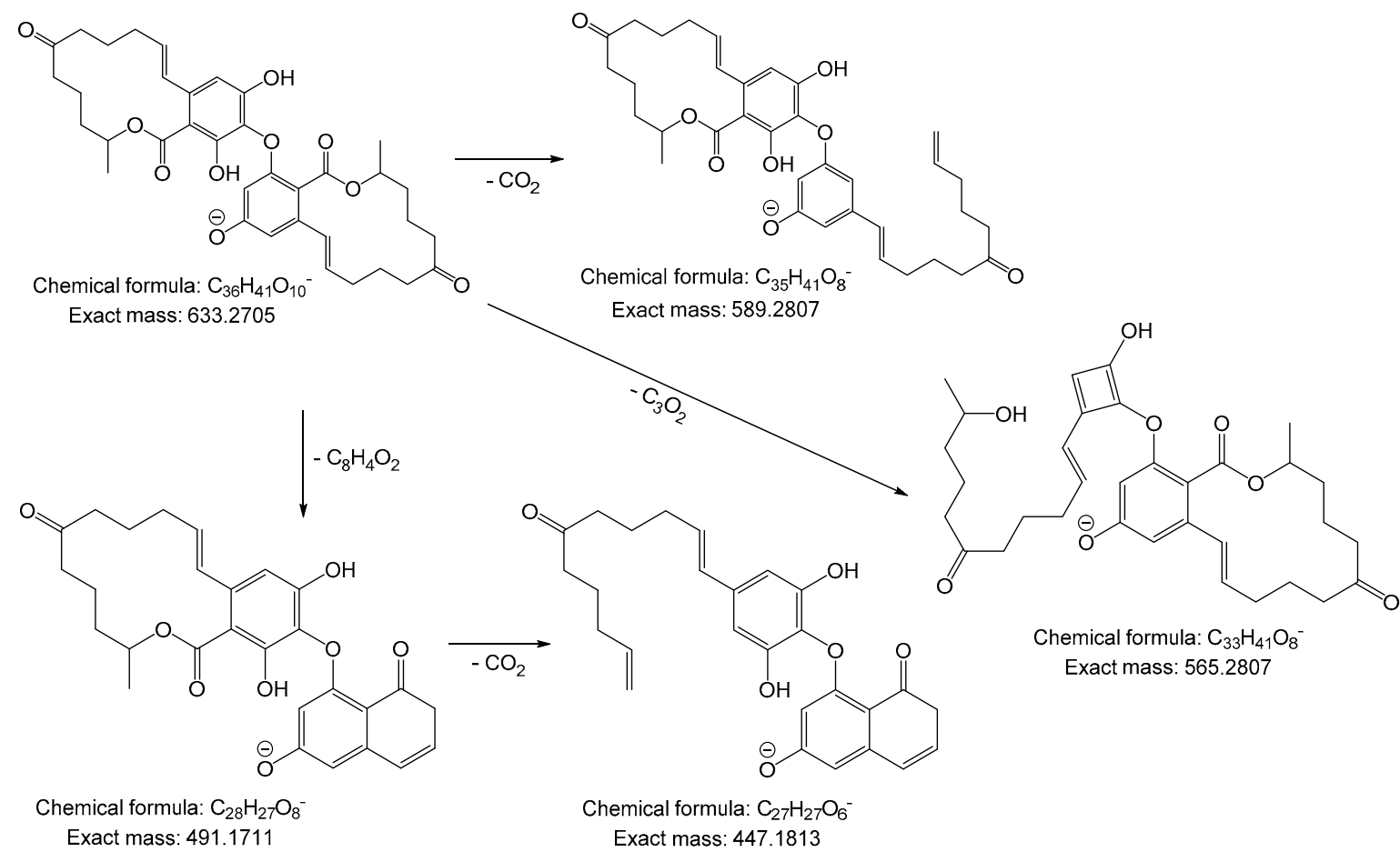

Figure 2. Postulated fragments of the ZEN-dimer, according to the MS/MS measurements with a molecular structure and formula along with the theoretical exact masses.

\section{Materials and Methods}

\subsection{Chemicals and General Experimental Procedures}

Zearalenone with a purity over 98\% was obtained from Fermentek (Jerusalem, Israel) and Cerium(IV)sulfate was purchased from Sigma-Aldrich (Steinheim, Germany). Ultrapure water was generated by a Seralpur PRO 90 CN system (Ransbach-Baumbach, Germany). All standard chemicals were of p.a. grade and all solvents were of an HPLC grade. Electrochemical oxidation was achieved by using the Roxy ${ }^{\circledR}$ system synthesis cell (Antec, Zoeterwoude, The Netherlands) equipped with a platinum working electrode. The HPLC system used for fractionation consisted of an Agilent 1200 series autosampler, a 1260 series pump, a 1200 series diode array detector, and a column oven. A Macherey-Nagel Nucleosil C18 100-5 $150 \times 4.6$ mm column (Düren, Germany) was used. The TripleTOF ${ }^{\circledR} 6600$ Quadrupole Time-Of-Flight (QTOF) mass analyzer (Sciex, Darmstadt, Germany) was operated in negative ionization mode and $10 \mu \mathrm{M}$ of the dimer sample were dissolved in methanol with $0.1 \%$ of formic acid. The used parameters were as follows:

Gas temperature $350^{\circ} \mathrm{C}$, ion source gas 1 (nitrogen) $20 \mathrm{~L} / \mathrm{min}$, ion source gas 2 (nitrogen) $15 \mathrm{~L} / \mathrm{min}$, curtain gas (nitrogen) $20 \mathrm{~L} / \mathrm{min}$, and ion spray voltage floating $-4500 \mathrm{~V}$. The MS/MS-spectrum was recorded in the targeted MS/MS mode with the following parameters: De-clustering potential $(-15 \mathrm{~V})$, collision energy $(-40 \mathrm{~V})$, and TOF Masses 100-640 Da. Confirmation of the 16-O-15'-biaryl ether-linked dimer structure was conducted by nuclear magnetic resonance spectroscopy (NMR). 
The NMR spectra were recorded in methanol- $d_{4}$ on an Agilent 400-MR NMR spectrometer (Agilent Technologies, Waldbronn, Germany) at $30^{\circ} \mathrm{C}$. For the measurements, the ATB 5mm-probe head was operated at $399.8 \mathrm{MHz}$ for ${ }^{1} \mathrm{H}$ and $100.5 \mathrm{MHz}$ for ${ }^{13} \mathrm{C}$ data.

\subsection{Electrochemical and Chemical Production of ZEN Dimer}

Electrochemical: The optimal potential was tested by taking aliquots after different time points and using potentials of $0,1.0,1.4$, and $1.8 \mathrm{~V}$ vs. $\mathrm{Pd} / \mathrm{H}_{2}$. For the electrochemical oxidation, $80 \mathrm{~mL}$ of $250 \mu \mathrm{M}$ $\mathrm{ZEN}$ in acetonitrile/water $(50 / 50, v / v)$ was stirred for $48 \mathrm{~h}$ using $1.4 \mathrm{~V}$ vs. $\mathrm{Pd} / \mathrm{H}_{2}$. The solution was subsequently evaporated to dryness by using a rotary evaporator and dissolved in water/acetonitrile $(65 / 35, v / v)$ for HPLC fractionation.

Chemical: For the oxidative production of ZEN dimers, Ce(IV)sulfate was used. About $100 \mathrm{mg}$ of ZEN and $350 \mathrm{mg}$ of Ce(IV)sulfate were dissolved in $200 \mathrm{~mL}$ of acetonitrile/water (50/50, $v / v)$ and stirred for two hours at $70{ }^{\circ} \mathrm{C}$. Subsequently, the sample was stirred for $24 \mathrm{~h}$ at room temperature and a white precipitate was formed. The yellow solvent mixture was extracted three times with $20 \mathrm{~mL}$ of ethyl acetate. After the extraction, the ethyl acetate was colored yellow and the acetonitrile water mixture was colorless. After evaporation, a deep orange and highly viscous fluid was obtained. After freeze-drying, a pale orange solid was formed with a yield of $10 \%$.

\subsection{Purification of ZEN Dimer}

For the separation of ZEN dimers, an already described HPLC method was adapted [15] by using a flowrate of $1.2 \mathrm{~mL} / \mathrm{min}$ and an isocratic eluent consisting of water/acetonitrile, 65/35, $v / v$ without modifiers. The ZEN dimer was isolated by collecting the fraction between $15.4 \mathrm{~min}$ and $16.2 \mathrm{~min}$ of the retention time by using a Foxy ${ }^{\circledR}$ R1 fraction collector (Teledyne ISCO, Nebraska, NE, USA). The purity of the dimer was determined to be $92 \%$ based on DAD spectra by using a wavelength at $\lambda=254 \mathrm{~nm}$ (Supplement Figure S7).

\section{Conclusions}

A new dimeric species of the food-relevant mycotoxin zearalenone was synthesized electrochemically and chemically with Ce(IV)sulfate and structurally identified. Among other possible dimers, the occurrence of the 16-O-15'-biaryl ether-linked dimer in food and feed is conceivable because the dimerization of phenolic compounds is often observed in plants, fungi, or lichen.

Supplementary Materials: The following are available online at http:/ / www.mdpi.com/1420-3049/23/10/2624/ s1, Figure S1. MS/MS fragmentation spectrum of the ZEN dimer obtained with Q-TOF in negative ionization mode. Figure S2. ${ }^{1} \mathrm{H}-\mathrm{NMR}$ spectrum of the $16-\mathrm{O}-15^{\prime}$-biaryl ether-linked zearalenone dimer. Figure S3. ${ }^{13} \mathrm{C}-\mathrm{NMR}$ spectrum of the $16-O-15^{\prime}$-biaryl ether-linked zearalenone dimer. Figure S4. COSY spectrum of the $16-O-15^{\prime}$-biaryl ether-linked zearalenone dimer. Figure S5. HMBC spectrum of the 16-O-15'-biaryl ether-linked zearalenone dimer. Figure S6. HSQC spectrum of the $16-O-15^{\prime}$-biaryl ether-linked zearalenone dimer. Figure S7. HPLC-DAD chromatograms $(\lambda=254 \mathrm{~nm})$ of the zearalenone dimer reaction mixture before fractionation (top) and after fractionation (bottom).

Author Contributions: Conceptualization, J.K. and L.H. Methodology, J.K., L.H., and M.K. Investigation, L.H. Data Curation, J.K. and M.K. Writing-Original Draft Preparation, J.K. Writing-Review \& Editing, H.H. and M.K. Supervision, M.K and H.H.

Funding: This research received no external funding.

Acknowledgments: The authors would like to thank René Kudick (ASCA GmbH, Berlin, Germany) for the NMR measurements and analytical advice.

Conflicts of Interest: The authors declare no conflict of interest. 


\section{References}

1. Caldwell, R.W.; Tuite, J.; Stob, M.; Baldwin, R. Zearalenone production by fusarium species. Appl. Microbiol. 1970, 20, 31-34. [PubMed]

2. Fraeyman, S.; Croubels, S.; Devreese, M.; Antonissen, G. Emerging fusarium and alternaria mycotoxins: Occurrence, toxicity and toxicokinetics. Toxins 2017, 9, 228. [CrossRef] [PubMed]

3. Placinta, C.M.; D'Mello, J.P.F.; Macdonald, A.M.C. A review of worldwide contamination of cereal grains and animal feed with fusarium mycotoxins. Anim. Feed Sci. Technol. 1999, 78, 21-37. [CrossRef]

4. Alexander, J.; Benford, D.; Boobis, A.; Ceccatelli, S.; Cottrill, B.; Cravedi, J.P.; Di Domenico, A.; Doerge, D.; Dogliotti, E.; Edler, L.; et al. Scientific opinion on the risks for public health related to the presence of zearalenone in food efsa panel on contaminants in the food chain. EFSA J. 2011, 9, 2197.

5. Hetmanski, M.T.; Scudamore, K.A. Detection of zearalenone in cereal extracts using high-performance liquid chromatography with post-column derivatization. J. Chromatogr. 1991, 588, 47-52. [CrossRef]

6. Koppen, R.; Riedel, J.; Proske, M.; Drzymala, S.; Rasenko, T.; Durmaz, V.; Weber, M.; Koch, M. Photochemical trans-/cis-isomerization and quantitation of zearalenone in edible oils. J. Agric. Food Chem. 2012, 60, 11733-11740. [CrossRef] [PubMed]

7. Drzymala, S.S.; Binder, J.; Brodehl, A.; Penkert, M.; Rosowski, M.; Garbe, L.-A.; Koch, M. Estrogenicity of novel phase $\mathrm{i}$ and phase ii metabolites of zearalenone and cis-zearalenone. Toxicon 2015, 105, 10-12. [CrossRef] [PubMed]

8. Pfohlleszkowicz, A.; Chekirghedira, L.; Bacha, H. Genotoxicity of zearalenone, an estrogenic mycotoxin-DNA adduct formation in female mouse-tissues. Carcinogenesis 1995, 16, 2315-2320. [CrossRef]

9. Binder, S.B.; Schwartz-Zimmermann, H.E.; Varga, E.; Bichl, G.; Michlmayr, H.; Adam, G.; Berthiller, F. Metabolism of zearalenone and its major modified forms in pigs. Toxins 2017, 9, 56. [CrossRef] [PubMed]

10. Borzekowski, A.; Drewitz, T.; Keller, J.; Pfeifer, D.; Kunte, H.-J.; Koch, M.; Rohn, S.; Maul, R. Biosynthesis and characterization of zearalenone-14-sulfate, zearalenone-14-glucoside and zearalenone-16-glucoside using common fungal strains. Toxins 2018, 10, 104. [CrossRef] [PubMed]

11. Brodehl, A.; Moller, A.; Kunte, H.J.; Koch, M.; Maul, R. Biotransformation of the mycotoxin zearalenone by fungi of the genera rhizopus and aspergillus. FEMS Microbiol. Lett. 2014, 359, 124-130. [CrossRef] [PubMed]

12. Kiessling, K.H.; Pettersson, H. Metabolism of zearalenone in rat liver. Acta Pharmacol. Toxicol. 1978, 43, 285-290. [CrossRef]

13. Bravin, F.; Duca, R.C.; Balaguer, P.; Delaforge, M. In vitro cytochrome p450 formation of a mono-hydroxylated metabolite of zearalenone exhibiting estrogenic activities: Possible occurrence of this metabolite in vivo. Int. J. Mol. Sci. 2009, 10, 1824-1837. [CrossRef] [PubMed]

14. Hildebrand, A.A.; Pfeiffer, E.; Rapp, A.; Metzler, M. Hydroxylation of the mycotoxin zearalenone at aliphatic positions: Novel mammalian metabolites. Mycotoxin Res. 2012, 28, 1-8. [CrossRef] [PubMed]

15. Keller, J.; Haase, H.; Koch, M. Hydroxylation and dimerization of zearalenone: Comparison of chemical, enzymatic and electrochemical oxidation methods. World Mycotoxin J. 2017, 10, 297-307. [CrossRef]

16. Wezeman, T.; Bräse, S.; Masters, K.-S. Xanthone dimers: A compound family which is both common and privileged. Nat. Prod. Rep. 2015, 32, 6-28. [CrossRef] [PubMed]

(C) 2018 by the authors. Licensee MDPI, Basel, Switzerland. This article is an open access article distributed under the terms and conditions of the Creative Commons Attribution (CC BY) license (http://creativecommons.org/licenses/by/4.0/). 